\title{
ENCRYPTED ECG DATA TRANSMISSION IN WIRELESS MEDIUM FOR HEALTH CARE APPLICATIONS
}

\author{
KALAIVANAN SUGUMAR ${ }^{1}$ and Balaji Ganesh $\mathrm{S}^{2}$ \\ ${ }^{1}$ SRM University \\ ${ }^{2}$ Saveetha University
}

May 27, 2020

\begin{abstract}
Current technological developments in the field of wireless communications has enabled the use of ultra-low power, lightweight, miniature types of smart health monitoring devices which are integrated into a Wireless Body Sensor Network (WBSN). Vital signs in humans such as temperature, heartbeat, and pulse can be tracked and detected from a remote location with help of biomedical wireless sensors. This article proposes a method to securely encrypt the patient's data and transmit it to the authorized doctor using wireless devices with in the hospital premises. This article is aimed at generating electrocardiogram (ECG) based key agreement scheme for the sake of generating a common key in a body area network. This kind of smart health information communication method by means of sensors and internet connection to servers is more confidential and encrypted to protect the patient's health data. Security and Privacy mechanisms use a significant part of the available energy and should therefore be energy efficient and light weight. The Proposed work in this article is implemented in Telosb running ContikiOS. The TelosB mote is designed for experimentation with low-power personal wireless area network (LoWPAN) with IEEE 802.15.4/ZigBee/Telosb compliant RF transceiver. By using iris or fingerprints, the security of this technique can be further improved.
\end{abstract}

\section{Hosted file}

Encrypted ECG data transmission-Wiley.docx available at https://authorea.com/users/326701/ articles/454716-encrypted-ecg-data-transmission-in-wireless-medium-for-health-careapplications

\section{Hosted file}

FIGURES.docx available at https://authorea.com/users/326701/articles/454716-encrypted-ecgdata-transmission-in-wireless-medium-for-health-care-applications 